\title{
Testing the Difference between School Level and Academic Mindset in the Classroom: Implications for Developing Student Psycho-Social Skills in Secondary School Classrooms
}

\author{
Janet Hanson (Corresponding author) \\ Department of Educational Leadership, Azusa Pacific University, Azusa (APU) \\ P.O. Box 7000, Rm 137, Azusa, CA 91702-7000, USA \\ Tel: 1-(626)-815-5375Ｅ-mail: jhason@apu.edu
}

Received: December 20, 2016

Accepted: January 24, 2017 Published: January 29, 2017

doi:10.5296/jei.v3i1.10479

URL: http://dx.doi.org/10.5296/jei.v3i1.10479

\begin{abstract}
This study explored the relationship between school level and the psychosocial construct of an academic mindset operationalized on the Likert-style Project for Educational Research That Scales (PERTS) instrument; widely used in testing academic mindset interventions at the classroom level. Analyses were conducted using existing school district data collected during the month of April, 2016, delivered to students, grades 3 through $8,(n=2,908)$ in the classroom at three elementary schools and two middles schools. The overarching research question was, "Is there a relationship between school level and students' academic mindset as measured by the PERTS scale?" Results revealed a significant decrease in the classroom PERTS scale mean scores between elementary classrooms $(\mathrm{n}=70)$ and secondary classrooms $(\mathrm{n}=50)$. A history of psycho-social construct theory and practical applications for the classroom are provided.
\end{abstract}

Keywords: Psycho-social factors, Classroom context, PERTS scale, Student transitions

\section{Introduction}

Mindset theory interventions involve the act of supporting students in taking autonomous action that aligns with their values and goals; such that they choose to engage and put effort into developing successful academic behaviors. This study seeks to answer the research question, "Is there a relationship between school level and a classroom's academic mindset culture?" Result of empirical tests and the literature review on the relevant topics may 
provide the classroom teacher with additional insights into context variables contributing to student autonomy, or choice to engage learning, in the classroom.

This study tests the influence of school level on academic mindset as operationalized on the PERTS instrument and to empirically test the relationships between psychosocial variables on the scale purported to comprise an academic mindset. When classroom teachers have reliable data collection instruments and understand the relationships between factors shown to contribute to student choice to engage, teachers can challenge their own assumptions in this area; identify key areas for growth; and learn additional skills to support student autonomous choice to engage the learning process.

Successful learning results in new skills that increases one's ability to act successfully in the world. An individual must choose to engage new experiences that challenge one's existing knowledge structures in order to develop meaningful learning that can transfer to new situations (Novak, 2002). Similarly, mindset theory builds on the theory of mind, or how one makes sense of the world (Hanson, 2015). However, learning requires personal effort and an openness to make corrections and changes in how one views his world. Similarly, an individual growth mindset, a factor of the academic mindset construct, has been described as the belief that one can grow and learn through one's efforts (Blackwell, Trzesniewski, \& Dweck, 2007).

Academic mindsets influence student learning because they contribute to students' beliefs about their abilities to predict and control their world, through one's a sense of self-efficacy. A person's sense of autonomy and control develops from experiencing a supportive social environment leading to positive experiences of individual development. Autonomy differs from independent action in that autonomous action involves an alignment with the values embedded in the actions undertaken. An autonomous person takes initiative, feels an intrinsic sense of control, and feels the tasks performed have relevance to him. A sense of belonging and social identity, with supportive others, is inherent in the process of reciprocal sense making (Hanson, in press). In contrast, independence is acting without help, support, or resources from others (Chirkov, Ryan, Kim, \& Kaplan, 2003).

\subsection{Purpose Statement}

This study tested the relationship between school level and the student psycho-social construct of an academic mindset in the classroom. This paper provides a discussion of psycho-social variables found in the literature under the description of academic mindsets in the classroom. Current research seeks to develop valid conclusions drawn from reliable data. Analysis of data collected in the area of psycho-social variables has been shown to support student learning, including the variables of individual mindset, student sense of belonging in the classroom, classroom task relevance, and student self-efficacy on classroom tasks (Bandura, 2001; Deci \& Ryan, 1994; Dweck, 1986; Hanson \& Bangert, 2017; Ma, 2003; Paunesku, Romero, Yeager, Walton, \& Dweck, 2014).

These variables have been operationalized on the Project for Educational Research That Scales (PERTS) instrument (PERTS, 2015a). Research suggests that students with high 
academic mindsets engage academic behaviors such as attending class, homework completion, organizing work, and studying leading to improved learning outcomes (para. 5). The PERTS research team's mission statement and purpose for designing the PERTS scale is "to improve the equity of learning outcomes by bridging the gap between cutting-edge research and implementation practices ..." (PERTS, 2015b, para. 2).

\subsection{Problem Statement}

Prior research suggested students changing from elementary to secondary schools showed reduced academic engagement (Hanson, Ruff, \& Bangert, 2016). The literature on boundary crossing suggested that when students change school levels they experience significant differences in school cultures contributing to student choice to withdraw from academic engagement. Secondary level teachers were also described in the literature as demonstrating fewer skills to support student psycho-social skill development. Student emotional development also changes during their secondary school years and many secondary level teachers lack skills for developmentally appropriate responses to students' needs and this can result in reduced student pro-social behaviors (Eccles \& Wigfield, 2002; Farrington et al., 2012, p. 63). Teachers at the secondary level were also described as using teaching practices that reduced student autonomy and developed fewer teacher-student relationships. Both of these factors have been shown to significantly affect student success on classroom tasks (Blackwell et al., 2007; Spector, 1988).

Understanding the influence of the teacher on the classroom context in relationship to developing student engagement is a necessary part of successful teaching. Historically assessment measures in schools have largely focused on cognitive variables demonstrating learning outcomes of students and school effectiveness. Current research is exploring psycho-social influences. Therefore, testing the relationship of school level on the psychosocial variable of academic mindset in the classroom could provide additional insights into ways to support classroom teachers in understanding and developing improvements in their classroom teaching practices to help students' choice to engage academic behaviors.

\subsection{Research Questions}

The overarching research questions for this study included:

Is there a relationship between school level and the classroom mean scores of students' academic mindset as measured by the PERTS instrument?

Is there a relationship between the individual factors operationalized on the Project for Educational Research That Scales (PERTS) instrument?

\subsection{Definitions}

Academic mindset: Farrington et al. (2012) described academic mindset as the "beliefs, attitudes, or ways of perceiving oneself in relation to learning and intellectual work that support academic performance" (p. 28). The four distinct academic mindsets include beliefs of belonging; the ability one can grow through effort; that one can succeed on classroom tasks; and that the work required has value. 
Boundary crossing: is "a person's transitions and interactions across different sites," (Suchman, 1994, p. 25 in Middleton \& Baartman, 2013).

Student sense of belonging: (Items 4-7) Goodenow and Grady (1993) in Ma (2003) defined sense of belonging as "the extent to which students feel personally accepted, respected, included, and supported in the school social environment" (p. 340).

Student individual mindset: (Items 1-3 reversed scored) has been described as "the way in which children interpret human behavior and their beliefs about the stability of human traits." (Heyman \& Dweck, 1998, p. 391).

Self-efficacy: (Items 12-15) "A mechanism of personal agency, the belief about one's ability to exercise control over other events that affect their lives." Self-efficacy beliefs affect thought patterns and influence one's choice of goals and commitment to them (Bandura, 1989, p. 1175). Self-efficacy is an expectancy theory. A student with high self-efficacy for a certain task, would expect to be able to accomplish that task within the given context. Self-efficacy beliefs are comprised of two components: first is a belief that a specific behavior will produce an outcome, and secondly, the belief in one's personal efficacy to produce that behavior in the present context and in future situations (Goddard, 2002).

Classroom task relevance: (Items 8-11) “A student's sense that the subject matter he or she is studying is interesting and holds value. Value can be variously defined as the importance of doing well on a task (attainment value); gaining enjoyment by doing a task (intrinsic value); or serving a useful purpose or meeting an end goal that is important by completing a task (utility value)" (Eccles et al., 1983 in Farrington et al., 2012, p. 10).

\section{Literature Review}

A variety of models have been developed to explain how people learn, including; Watson (1924), Skinner (1953, 1954), and Pavlov's (1927) work in behaviorism; Piaget's (1952) theory of cognitive development using the clinical interview process; Vygotsky's (1978) cognitive sociocultural learning model and zone of proximal development; and Bandura's (2001) social cognitive theory. Dweck's (1986) work in the concept of individual personality theories of fixed and growth mindset was deeply rooted in the framework and history of social cognitive theory. This present study tests a Likert-style instrument purported to quantity variables found in the theory of academic mindsets; adding to the individual mindset learning theory by collecting data at the group/classroom level (Farrington et al., 2012).

Researchers and philosophers alike have developed theories of the mind. For example, Kant (1787/1999) declared the individual's mind constructed one's view of reality; the beginning of the constructivist viewpoint. Hegel (1807/1967) considered individual thought to be influenced by one's social group in a reciprocal exchange of meaning creation. Marx (1867) described the influence of one's context on the creation of the individual's thought.

Theorists in the field of education, such as Dewey (1938/1997), and Vygotsky (1962), later advanced the idea that the social environment and the individual influenced each other in a reciprocal process of learning. This distinction becomes a foundation for understanding 
Bandura's (2001) social cognitive theory and its triadic model of reciprocal influence of; human cognition, one's environment, and the influence of social modeling on the behavior of the learner. Bandura explained, "... human functioning is rooted in social systems" (p. 15).

Organizational learning theories, resulting from research such as the Hawthorne experiments, described the reciprocal influence of the individual and organization. Variables influencing organizational learning include leader openness to change, faculty openness to change, work locus of control, goal alignment, and collective efficacy (Hanson, Ruff, \& Bangert, 2016). Collective efficacy has been tested and shown to explain improved organizational outcomes (Tarter \& Hoy, 2004). Results of organizational learning research are integral in developing teachers' understanding of how to support student learning in the context of the classroom (Senge, 1990, 2000; Hoy, Tarter, \& Kottkamp, 1991; Collinson \& Cook, 2007).

Similarly, researchers described unconscious processes that influenced learning. These processes were considered the result of differences in one's culture of origin; such as western individualistic and eastern collectivist viewpoints. The philosopher, René Descartes (1633/1999) described a distinction between the mind and the body setting the foundation for the dualistic worldview that influences western thought to this day. The dualistic view resulted in the scientific method and in a symptomatic approach to treating illnesses.

However, this isn't the only way to view the world. Current organizational learning theories describe an organic model as opposed to a reductionist, or mechanistic, model. The organic model is a holistic approach and can be shown to influence a cultures' approach to medicine, research, and system organization (Hanson, 2015). Following is a discussion on the progression of learning theories' psycho-social variables set in a framework of an integrated approach to systems.

\subsection{Psycho-Social Influences on Learning}

\subsubsection{Conscious and Unconscious Processes Influencing Learning}

Some researchers are suggesting new models for thinking about the brain and new models for describing how we learn. These newer models usually include learning as socially constructed and dependent on both implicit and explicit processes of knowing. This distinction becomes a foundation for understanding Bandura's (2001) social cognitive theory and its triadic model of reciprocal influence including: the human cognition, one's environment, and the influence of social modeling on the behavior of the learner.

\subsubsection{Historical Roots of Fixed and Growth Mindset}

Growth and fixed mindset concepts compare favorably to the nature versus nurture debate popularized in Francis Galton's works $(1874,1889)$. Current discussions revolve around whether we are born with our abilities and traits; that is, to ask whether one's traits, such as intelligence, cannot be changed or if one can develop the brain's abilities over time through applying effort and with appropriate social support and resources. Many researchers consider that both nature and nurture contribute to the development of an individual's skills and the resulting success of individuals (Hanson, 2015). 


\subsubsection{Behaviorism}

Bandura's experiments were among the first to report the powerful influence of nurture, or social influence, on individual learning. Prior to Bandura's research, educational models of learning focused largely on behaviorism. Pavlov's experiments with stimulus response procedures to develop salivation in dogs is well known and supports the teaching models of many educational curriculum and classroom management models. Stimulus response theory suggested humans learned through a series of rewards and punishments, without reference to cognitive choice or the influence of one's social group. The behaviorists' experiments were performed using animals, not humans. Some researchers felt studying cognition was not possible because the mind could not be seen; so the focus of the research was on observable behaviors.

\subsubsection{Social Cognitive Theory}

The social cognitive theory was developed from the results of a collection of experiments by Bandura. In his famous bobo doll experiment, he saw a child acting aggressively toward a doll after the child had observed an adult inadvertently model that behavior. Bandura developed the conclusion that imitation is a powerful social influence on individual learning (Bandura, D. Ross, S. Ross, \& Webb, 2013).

\subsection{Mindset Theory}

Dweck (1986) researched and developed a model of growth and fixed mindset at Stanford University, where Bandura also worked while developing the social cognitive theory. Dweck's development of the concept of mindset is deeply rooted in the framework and history of social cognitive theory. Researchers continue to explore the concept of mindset and have expanded the concept to new models at the group level. The organizational learning models attempt to capture variables inherent in the influence of one's social context. The group level mindset models are consistent with social cognitive theory explaining the reciprocal influences of the group on the development of individuals' beliefs, choices, and behaviors. Figure 1 shows factors on three levels of mindset scales; individual, group/classroom, and school. 

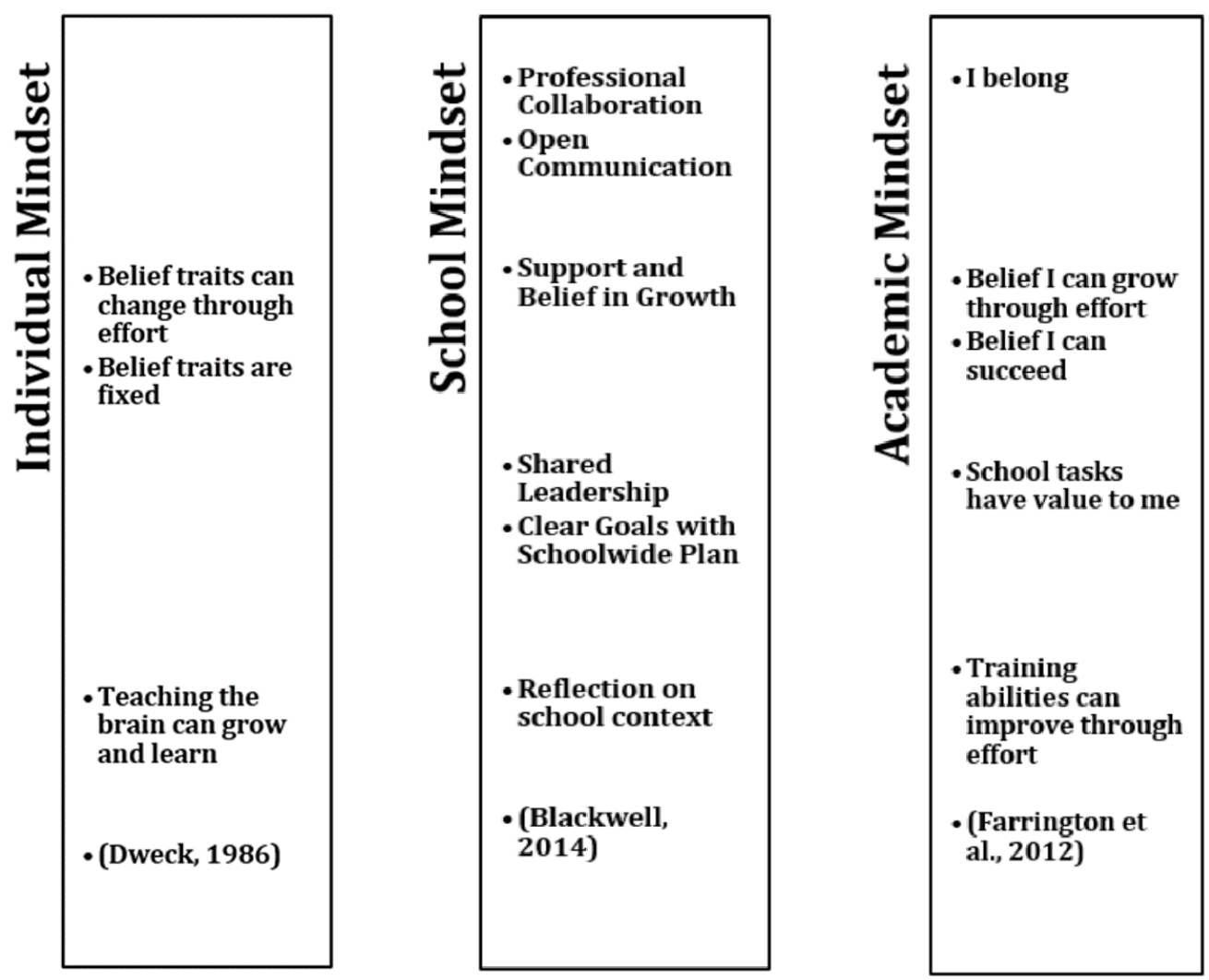

CHanson, 2016.

Figure 1. Model comparing and contrasting variables on three levels of mindset surveys

The above figure shows the categories of variable items included on the individual mindset survey, PERTS survey, and What's My School Mindset Survey (WMSM). The Likert-style surveys are used to quantify participant self-reports of their perceptions of psycho-social variables, found in the literature, and reported to improve student engagement in the learning process.

\subsubsection{Academic Mindset}

Researchers described academic mindsets as ways students think of themselves that make them want to learn (Farrington et al., 2012, p. 9). The concept of academic mindset adds to the individual mindset construct. Along with an individual mindset belief, the academic mindset concept includes a student's belief that he belongs, feelings of relevance for the tasks required of him, and a belief that he can perform the tasks (self-efficacy) required of him in the classroom. Students with higher academic mindsets demonstrate higher levels of academic behaviors such as study, attendance, and homework completion (PERTS, 2015a, para. 5).

Academic mindsets are associated with behaviors that have large effects on student learning. Mindset as a psycho-social construct compares favorably with self-efficacy described as "... a mechanism of personal agency, the belief about one's ability to exercise control over other 
events that affect their lives" (Bandura, 1989, p. 1175). While mindset and self-efficacy are similar in their influence on personal agency, they differ in that mindset is a belief about the malleability of one's traits, whereas self-efficacy is a belief in one's abilities to perform a task. One's mindset has an indirect influence on successful academic outcomes through the influence it has on developing one's self-efficacy beliefs (Hanson, 2015).

\subsubsection{School Mindset Culture}

Mindset researchers have added variables to the individual mindset construct to create a group/classroom level construct of academic mindset. For the organizational level, researchers have developed the What's My School Mindset? Survey (Mindset Works, 2015) to capture and quantify faculty perceptions of a school growth mindset culture. Research studies suggested interventions at the individual level show less potential for improving outcomes than those done at the group and organizational levels (Hanson, Ruff, \& Bangert, 2016). For example, Osterman (2000) found variables within the school context, and instructional methods, that can be influenced by administrators and faculty. These variables were also shown to develop academic mindsets in students (Blackwell et al., 2007; Dweck, Walton, \& Cohen, 2014). The Project for Education Research that Scales (PERTS) performs studies on the impact of mindset interventions on classroom outcomes using the PERTS scale (PERTS, 2015a). The next section provides a discussion classroom level variables shown to support student academic mindsets.

\subsubsection{Systems Thinking}

A leader's behavior influences an overall perception of how the organization will perform (Bohn, 2002, p. 76). One way to improve an organization, is to promote self-organizing behaviors in the participants. Viewing the classroom as a system, teachers can support the development of individual roles and team skills that enable the system to self-organize by creating common expected norms of behavior. When students behave according to expected norms, they contribute to improvements and structures that are meaningful to them. An instructor's use of modeling, such as pacing and leading, requires a bird's eye view of the classroom and a systems thinking perspective (Senge, 2000).

\subsection{PERTS Factors}

A review of the literature in the areas of mindset, meaningful learning, theories of mind, and psycho-social factors contributing to student engagement revealed a common element of autonomous action within a social context. Student autonomy develops when students feel; a sense of belonging and social identity with supportive others in the classroom; that they are an inherent part of the process of reciprocal sense making; classroom goals are aligned with their personal goals and values; there are opportunities to take initiative; and their personal values are embedded into the tasks required providing a feeling of personal and life relevance (Hanson, 2017).

\subsubsection{Self-efficacy on Classroom Tasks}

Self-efficacy develops from positive feedback in social relationships and opportunities to 
practice skills together. Four variables contribute to the development of self-efficacy: mastering a task, observing others successfully performing the task, being told by valued others that he can be successful, and developing one's ability to manage one's own stress states (Versland, 2009). Balancing the roles between integration (system role) and independent action (individual role) is a key variable for developing a flexible focus that allows students to shift from one perspective to another as best fits the context at the moment. Autonomous functioning is the ability to flexibly shift between social and independent action.

Goal alignment is a key factor in developing individual self-efficacy and group collective efficacy. The teacher can develop a classroom level social identity among the students by modeling and encouraging students to: acknowledge one another and agree on common goals and means. Differences may remain as long as a common vision is achieved. What you agree on and how to come to agreement is different from classroom to classroom (Hanson, in press).

Modeling by the classroom teacher influences the classroom system and indirectly the individual students. Modeling has been shown to be an effective way to build positive classroom culture and promote student self-efficacy (Bandura, 2001, Dweck, 2010, Hanson, 2015). An example of a teacher modeling is called pacing and leading. The teacher observes the classroom behaviors and where there is a departure from the expectations, the teacher first identifies with the students' current focus through movement and supportive comments. Next, inviting the students to participate in the desired activity includes an opportunity for autonomous action to engage in personally relevant activities aligned with classroom goals.

A teacher can embed multiple opportunities for students to master the tasks required while providing sufficient psycho-social support through positive feedback such as explicit tasks for how to improve. Supportive teacher behaviors include allowing sufficient time for the students to practice the expected tasks over many trials until they master the behavior sufficiently to perform the tasks independently. Where necessary, model and provide explicit instruction on how to manage one's own stress responses.

\subsubsection{Sense of Belonging in the Classroom}

In Maslow's (1943) hierarchy of needs theory, belonging is considered a basic human need. Schwarz (1990) included sense of belonging as a part of security in his model of motivational types of values. A students' sense of belonging has been connected with developing positive relationships. Teachers can develop a sense of belonging for students in the classroom by: providing opportunities for team collaboration and identifying each student's role in the group; being explicit and clear; matching the students' strengths and personal role identities with the role in the team; allowing students to give feedback on their experiences in the group; responding to their suggestions; and ensuring the group activity develops positive interaction with others (Deci \& Ryan, 1994).

Teachers must ensure to provide equitable and just classroom systems and processes. When the leader's formal (position) is integrated with the informal (relational) position one develops a sense of "... moral authority on their subordinates by establishing synchrony in 
their words and actions; the rest of the structure and processes of the organization also get aligned for it, thus creating a robust and transparent culture" (Sidik, 2013, slide \# 25).

\subsubsection{Classroom Task Relevance}

A next step in the process of developing academic mindsets in students is to provide real world educational opportunities for students and to connect these to students' prior learning. A teacher can develop task relevance by providing a purpose for the activities that the students can understand. Connect with students to develop an understanding of their personal interests and align the classroom tasks to these values. Provide real world educational opportunities for students to develop a sense of life relevance.

\subsubsection{Student Individual Mindset}

Developing a growth mindset classroom culture and providing supportive classroom contexts with an understanding of the importance of praising effort rather than traits will contribute to student growth mindsets (Farrington et al., 2012). Well-being increases when an individual's mindset matches the organization's mindset (Delaney, Dweck, Murphy, Chatman, \& Kray, 2015). However, research suggests the individual's mindset has little correlation with the group level mindset culture in schools. Organizational values and norms can differ from individual norms, yet, individuals can agree to participate in the overall activities of the group through internalizing the goals of the group (Hanson, in press).

\section{Methods}

This study used a quantitative research design and existing data from a mid-size, rural school district in a large southwestern state. The school district collected data on the schools' cultures and climate for use in setting Local Control and Accountability Planning (LCAP) goals.

\subsection{Data Sources and Participants}

The school district collected LCAP survey data during the month of April, 2016, using a variety of Likert-style surveys delivered to students, grades 3 through 8 , (n $=2,908 ; 84 \%$ response rate) in the classroom at three elementary schools and two middles schools; faculty participants included teachers, grades TK-8, $(\mathrm{n}=224)$, other certificated personnel $(\mathrm{n}=9)$, and administrators $(\mathrm{n}=11)$.

\subsection{Instrumentation}

The data used in this study was collected by the district for LCAP data collection and included a brief demographic questionnaire plus 15-items of the Project for Educational Research the Scales (PERTS) instrument, which included four sub-scales; individual mindset (3 items), sense of belonging in the classroom (4 items), task relevance (4 items), and self-efficacy on classroom tasks (4 items). Respondents self-reported their agreement with scale items by providing ratings on a Likert-style scale ranging from 1= Strongly Disagree, 2 $=$ Disagree, $3=$ Somewhat Disagree, $4=$ Somewhat Agree, $5=$ Agree, to $6=$ Strongly Agree .

Reliability data for the scales were; sense of belonging in the classroom, .820; self-efficacy on 
classroom tasks, .830; classroom task relevance, .820; and individual mindset, .772 (Hanson, 2017). Predetermined indices for an acceptable level for internal reliability of a widely used scale was Chronbach's alpha > .80 (Nunnally, 1978).

A variety of studies have been performed and reported in the literature demonstrating concept validity of the operationalized constructs on the PERTS scale (Farrington et al., 2012). The scale has strong face validity being currently used in large scale studies. The Appendix provides the PERTS scale items.

\subsection{Analyses}

\subsubsection{Testing for Normality of the Data}

The data collected in this study was evaluated for normality, skewness, and kurtosis using quantitative analytical software SPSS, 23 (IBM, 2015). The mean value of students' perceptions on their level of individual mindset, sense of belonging in the classroom, task relevance, and self-efficacy were calculated and correlation analysis was performed between the scales.

\subsubsection{Cross-Tabs}

Statistical analysis was performed to explore the interdependence of the demographic data variables and to identify statistically significant differences $(p<.05)$. One-way ANOVA analysis was used to compare the category means and determine any significant differences between groups that may affect the ability to generalize the results.

\subsubsection{Correlation and Regression Analysis}

A correlation analysis was performed and statistically significant correlations were evaluated further using regression analysis with dependent and independent variables identified consistent with the nomological net from the theory.

\section{Results}

\subsection{Testing for Normality of the Data}

Statistical analysis was performed on the results of the PERTS survey sample data to determine if the data fit a normal distribution and was considered reasonable for parametric analyses. Means and standard deviations for each variable were also explored for outliers that may influence the usefulness of the data for drawing valid conclusions that generalize to the population from which the data was drawn (Tabachnick \& Fidell, 2001). Tests for symmetry (skewness) and flatness (kurtosis) were performed using indices for acceptable limits of \pm 2 (Trochim \& Donnelly, 2006; Field, 2000, 2009; Gravetter \& Wallnau, 2014). All items tested were within acceptable limits.

\subsection{Cross-Tabs}

Table 1 shows the mean, standard deviation, and sample size for elementary and middle school levels from a One-way ANOVA analysis. 
Table 1. ANOVA results and Pearson Correlations between school building levels

\begin{tabular}{|l|l|l|l|l|}
\hline Factor & $M$ & $S D$ & Pearson's Coefficient (one-tailed) & $N$ \\
\hline Elementary** & 4.6599 & .7171 & $<.001$ & 70 \\
\hline Middle** & 4.4842 & .7717 & $<.001$ & 50 \\
\hline Total & 4.5790 & .7478 & & 120 \\
\hline
\end{tabular}

Note. ${ }^{* *} p=.001$, eta $^{2}=.014^{*}, F_{(1,118)}=11.819$.

\subsection{Correlation and Regression Analysis}

Significant positive relationships were found between variables of the PERTS scales as well as with gender and ethnicity. ANOVA tests on the data categories also revealed significant differences between PERTS scale factor mean scores by cultural identification. Students identifying as White and Asian self-scored significantly higher on the scale of self-efficacy for classroom tasks than other subcategories of students' culture. Gender had no significant effect on the regression outcome and was removed from the analysis.

The independent variables (IV) of belonging, task relevance, and individual mindset, along with ethnicity (described earlier) were entered simultaneously into the regression analysis using self-efficacy as the dependent variable consistent with the literature (Bandura, 2001).

The results from the multiple regression analysis revealed the IVs explained a significant proportion $\left(R^{2}=.276\right)$ of the variance in self-efficacy scores $\left(F_{(3,2,904)}=370.47, p<.001\right)$. The strongest predictor was student belonging $(\beta=.335)$, followed by task relevance $(\beta=.222)$, individual mindset $(\beta=.157)$. Table 2 shows $\beta$ and $\mathrm{p}$ values for the independent variables on SE.

Table 2. Regression of PERTS subscale means including $B, \beta$, and $p$ values

\begin{tabular}{|l|l|l|l|}
\hline $\begin{array}{l}\text { Variables from the literature considered } \\
\text { to explain variations in self-efficacy }\end{array}$ & $B$ & $\beta$ & $P$ \\
\hline Belonging & .334 & $.335^{* *}$ & $<.001$ \\
\hline Task Relevance & .235 & $.222^{* *}$ & $<.001$ \\
\hline Individual Mindset & .129 & $.157^{* *}$ & $<.001$ \\
\hline
\end{tabular}

Note. $R=.527$ and adjusted $R^{2}=.277^{* *}, d f=4, n=2,903 ; F=279.625$.

Figure 2 shows a model of the relationships between the variables of the PERTS scales. 


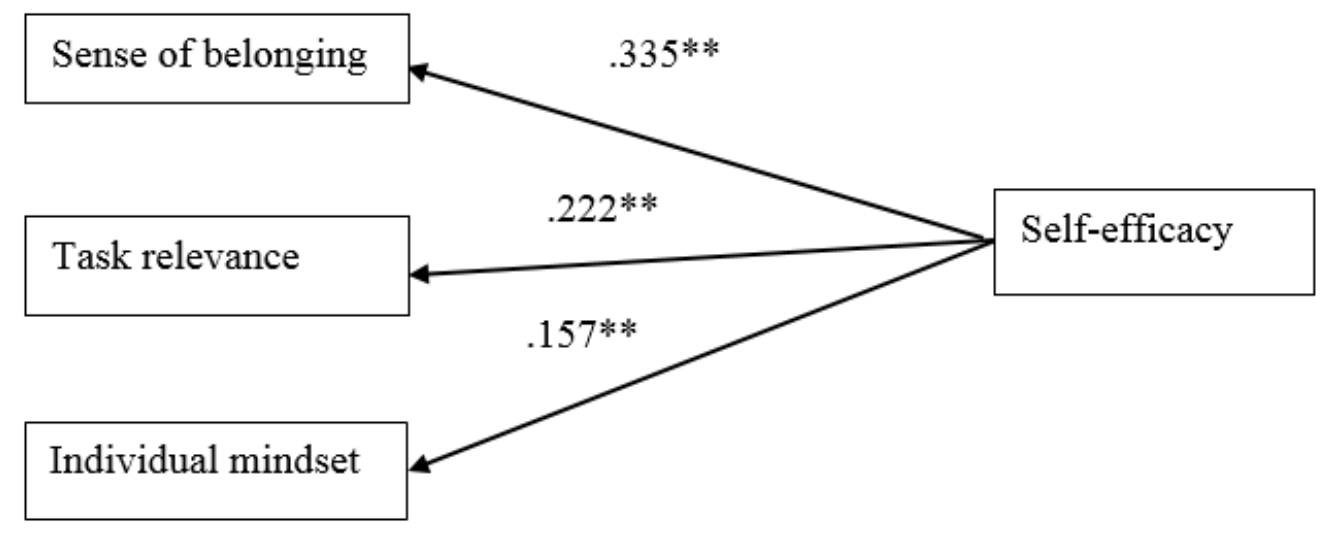

Figure 2. Model of PERTS subscale variables relationships

Note. ${ }^{* *}: p<.001$.

\section{Summary and Conclusion}

\subsection{Research Questions}

The following sections provide a discussion of how the overarching research questions of this study were answered using results from empirical tests of the data collected on the PERTS scale in three elementary schools and two middles schools $(n=2,908)$ in a rural district in a large southwestern state of the United States.

\subsubsection{Research Question \#1}

The research question,

Is there a relationship between school level and the classroom mean scores of students' academic mindset as measured by the PERTS instrument?

was answered by the results of a one-way ANOVA analysis comparing the classroom PERTS scale means between elementary $(n=70)$ and secondary level $(n=50)$ groups. Significant variations in the sample data were noted between the building levels. This is consistent with Blackwell et al. (2007), and Hanson, Ruff, and Bangert's (2016) research on school transition and boundary crossing effects from elementary to middle and high schools. Hanson et al. used the What's My School Mindset? instrument to quantify the psycho-social construct of a school's growth mindset culture.

\subsubsection{Research Question \#2}

The results of this study answered the question, "Is there a relationship between the individual factors operationalized on the Project for Educational Research That Scales (PERTS) instrument?" using results from correlation and regression analyses. All three independent variable scale factors significantly correlated with the dependent variable self-efficacy. Regression of the independent variables on the dependent variables revealed sense of 
belonging showed the greatest influence to explain variations in the self-efficacy mean. Together the three independent factors explained a small but significant effect $\left(R^{2}=.276\right)$ of the overall variation in SE mean scores. Teachers can expect that student self-efficacy may improve when students receive psychosocial supports leading to improved sense of belonging, task relevance, and individual mindset.

\subsection{Implications}

Implications for classroom teachers suggest developing skills to provide psycho-social supports to students at the secondary level may be a useful intervention to develop student academic mindsets leading to autonomy and choice to engage learning. Teachers can use this information to recognize differences exist in student perceptions of the psychosocial supports they receive in the classroom at the middle school level compared to the elementary level. The following recommendations provide insight into ways teachers can support the development of student psycho-social skills in the classroom context.

\subsection{Recommendations}

School leaders can use data collected from the PERTS scale to develop goals for developing positive classroom cultures that support student transitions between school levels (Hanson, Ruff, \& Bangert, 2016), as a boundary object evidencing the effects of differing school levels on student psycho-social factors in the classroom, and to identify areas of need for professional development for classroom teachers' skills at providing students with psycho-social supports. The following recommendations for classroom teachers include strategies for classroom interventions to support the development of secondary school teacher's skills at providing psycho-social supports to students to improve choice to engage learning.

\subsubsection{Teacher Influence}

Factors of an academic mindset have been shown to be malleable to administrator and teacher influence. Teachers can support the development of academic mindset culture in the classroom through modeling, social persuasion, providing mastery experiences, explicitly teaching students the skills necessary to manage their psychological and emotional states (Versland, 2009).

\subsubsection{Developing Teams}

When students develop social identities through interacting in classroom collective activities their sense of belonging increases and promotes autonomous functioning, reducing the number of decisions that must go through the teacher (Walton, 2014).

\subsubsection{Aligning Student Individual Identities with Classroom Roles}

Aligning students' personal interests and goals with group activities, classroom goals, and task relevance promotes student choice to engage in the learning activities.

\subsubsection{Develop Social Experiences of Support}

Teachers can provide positive feedback and psycho-social support for student effort by not 
focusing on immediate success. When teachers frame failed learning attempts as necessary practice to develop successful outcomes over time, provide social persuasion that the student can succeed, and resources of time and explicit tasks for improvement, students have been shown to develop improvements in their individual growth mindset beliefs (Bandura, 1994; Claro \& Dweck, 2016).

\subsection{Recommendations for Further Research}

Future studies might include qualitative interviews of students to develop a rich, thick, understanding of their experiences in the classroom and how they perceive the scale constructs of the PERTS instrument and strategies for improving psycho-social supports of individual mindset, task relevance (related to goal alignment), student sense of belonging, and student self-efficacy on classroom tasks.

\section{References}

Bandura, A. (1989). Regulation of cognitive processes through perceived self-efficacy. Developmental Psychology, 25(5), 729-735. https://doi.org/10.1037/0012-1649.25.5.729

Bandura, A. (1994). Self-efficacy. In V. S. Ramachaudran (Ed.), Encyclopedia of human behavior (Vol. 4, pp. 71-81). New York: Academic Press. [Reprinted in H. Friedman (Ed.), Encyclopedia of mental health. San Diego: Academic Press, 1998].

Bandura, A. (2001). Social cognitive theory: An agentic perspective. Annual Review of Psychology, 52, 1-26. https://doi.org/10.1146/annurev.psych.52.1.1

Bandura, A., Ross, D., Ross, S., \& Webb, D. (2013). Psychology classics all psychology students should read: The bobo doll experiment. CreateSpace Independent Publishing Platform.

Blackwell, L. S., Trzesniewski, K. H., \& Dweck, C. S. (2007). Implicit theories of intelligence predict achievement across an adolescent transition: A longitudinal study and an intervention. Child Development, 78, 246-263. https://doi.org/10.1111/j.1467-8624.2007. 00995.X

Bohn, J. G. (2002). The relationship of perceived leadership behaviors to organizational efficacy. The Journal of Leadership and Organizational Studies, 9(1), 66-79. https://doi.org/10.1177/107179190200900206

Chirkov, V., Ryan, R. M., Kim, Y., \& Kaplan, U. (2003). Differentiating autonomy from individualism and independence: A self-determination theory perspective on internalization of cultural orientations and well-being. Journal of Personality and Social Psychology, 84(1), 94-110. https://doi.org/10.1037/0022-3514.84.1.97

Claro, S., Paunesku, D., \& Dweck, C. S. (2016). Growth mindset tempers the effects of poverty on academic achievement. Proceedings of the National Academy of Sciences of the United States of America, 113(31), 8664-8668. https://doi.org/10.1073/pnas.1608207113

Collinson, V., \& Cook, T. (2007). Organizational learning improving learning, teaching, and 
leading in school systems. Thousand Oaks: Sage Publications.

Deci, E. L., \& Ryan, R. M. (1994). Promoting self-determined education. Scandinavian Journal of Educational Research, 38, 3-14. https://doi.org/10.1080/0031383940380101

Delaney, S., Dweck, C., Murphy, M., Chatman, J., \& Kray, L. (January 1, 2015). New study findings: Why fostering a growth mindset in organizations matters. Retrieved March 15, 2015, from http://senndelaney.com/SD_growthmindsetstudy.html

Descartes, R. (1633/1999). Discourse on method and meditations on first philosophy. New York, NY: Hackett.

Dewey, J. (1938/1997). Experience and education. Macmillan.

Dweck, C. (1986). Motivational processes affecting learning. American Psychologist, 41(10), 1040-1048. https://doi.org/10.1037/0003-066X.41.10.1040

Dweck, C. S. (2010). Mind-sets and equitable education. Principal Leadership (pp. 26-29). Retrieved from http://www.principals.org/Content.aspx?topic=61219

Dweck, C., Walton, G. M., \& Cohen, G. L. (2014). Academic tenacity: Mindsets and skills that promote long-term learning. Bill \& Melinda Gates Foundation. Retrieved from https://ed.stanford.edu/sites/default/files/manual/dweck-walton-cohen-2014.pdf

Farrington, C., Roderick, M., Allensworth, E., Nagaoka, J., Seneca-Keyes, T., Johnson, D., \& Beechum, N. (June 1, 2012). Teaching adolescents to become learners: The role of noncognitive factors in shaping school performance. Chicago consortium on Chicago school research. Retrieved December 10, 2016, from https://consortium.uchicago.edu/publications/ teaching-adolescents-become-learners-role-noncognitive-factors-shaping-school

Field, A. (2000). Discovering statistics using SPSS for windows. London-Thousand Oaks-New Delhi: Sage publications.

Field, A. (2009). Discovering statistics using SPSS. London: SAGE.

Galton, F. (1883). Inquiries into human faculty and its development. London: J.M. Dent \& Co. https://doi.org/10.1037/14178-000

Goddard, R. D. (2002). A theoretical and empirical analysis of the measurement of collective efficacy: The development of a short form. Educational and Psychological Measurement, 93, 467-476. https://doi.org/10.1177/0013164402062001007

Gravetter, F., \& Wallnau, L. (2014). Essentials of statistics for the behavioral sciences (8th ed.). Belmont, CA: Wadsworth.

Hanson, J. L. (2015). Determination and validation of the "What's My School Mindset?" instrument factor structure (Order No. 3722197). Dissertations \& Theses at Montana State University: ProQuest Dissertations \& Theses Global.

Hanson, J. L. (in press). Manage your mindset: Maximize your power of personal choice. Lanham, MD: Rowman \& Littlefield. 
Hanson, J. (2017). Determination and Validation of the Project for Educational Research That Scales (PERTS) Survey Factor Structure. Journal of Educational Issues, 3(1), 64-80. http://dx.doi.org/10.5296/jei.v3i1.10646

Hanson, J., Ruff, W., \& Bangert, A. (2016). Investigating the relationship between school level and a school growth mindset. Journal of Educational Issues, 2(2), 203-221. http://dx.doi.org/10.5296/jei.v2i2.10052

Hegel, G. W. F. (1807/1967). In J. B. Baillie (Trans.), Phenomenology of spirit. New York, NY: Harper \& Row.

Heyman, G., \& Dweck, C. (1998). Children's thinking about traits: Implications for judgments of the self and others. Child Development, 64(2), 391-403. https://doi.org/10.1111/j.1467-8624.1998.tb06197.x

Hoy, W., Tarter, C., \& Kottkamp, B. (1991). Open schools/healthy schools measuring organizational climate. Newbury Park: Sage Publications.

IBM Corp. (2015). IBM SPSS Statistics for MacIntosh (Version 23.0). Armonk, NY: IBM Corp.

Kant, I. (1787/1999). Critique of pure reason. Cambridge, UK: Cambridge University Press.

Ma, X. (2003). Sense of belonging to school: Can schools make a difference? Journal of Educational Research, 96(6), 1-9. http://dx.doi.org/10.1080/00220670309596617

Marx, K. (1867). Das kapital: Kritik der politischen oekonomie (Vol. I). Hamburg, Germany: Otto Meisner.

Maslow, A. H. (1943). Motivation and personality. New York: Harper \& Row.

Middleton, H. E., \& Baartman, L. K. J. (Eds.). (2013). Transfer, Transitions and Transformations of Learning. Rotterdam, The Netherlands: Sense Publishing. http://dx.doi.org/10.1007/978-94-6209-437-6

Mindset Works, Inc. (2015). What's My School Mindset? (para. 5). Retrieved October 26, 2016, from https://www.mindsetworks.com/assess/

Novak, J. (2002). Meaningful learning: The essential factor for conceptual change in limited or inappropriate propositional hierarchies leading to empowerment of learners. Science Education, 86(4), 548-571. https://doi.org/10.1002/sce.10032

Nunnally, J. C. (1978). Psychometric theory (2nd ed.). New York: McGraw-Hill.

Osterman, K. F. (2000). Students' need for belonging in the school community. Review of Educational Research, 70(3), 323-367. https://doi.org/10.3102/00346543070003323

Paunesku, D., Romero, C., Yeager, D., Walton, G., \& Dweck, C. (2014). Changing mindsets to raise achievement: Evidence from the Stanford University Project for Education Research That Scales (Executive Summary). Retrieved December 10, 2016, from https://p3.perts.net/static/documents/PERTS_Summary_January_2014.pdf 
Pavlov, I. P. (1927). In G. V. Anrep (Trans.), Conditioned reflexes. London: Oxford University Press.

PERTS. (2015a). Academic Mindsets Assessment. Retrieved December 10, 2016, from https://mindsetmeter.appspot.com/share/dlmooc

PERTS. (2015b). Our Mission. Retrieved December 12, 2016, from https://www.perts.net/about

Piaget, J. (1952). The origins of intelligence in children. New York: International Universities Press. https://doi.org/10.1037/11494-000

Senge, P. (2000). Schools that learn: A fifth discipline fieldbook for educators, parents, and everyone who cares about education. New York: Doubleday.

Senge, P. M. (1990, revised 2006). The fifth discipline: The art \& practice of the learning organization. New York: Doubleday.

Sidik, Y. M. (2013). Communication in public administration. Slideshare. Retrieved from http://www.slideshare.net/yhamskiey/communication-in-public-administration-16321538?nex t_slideshow $=1$

Skinner, B. F. (1953). Science and human behavior. New York: Free Press.

Skinner, B. F. (1954). The science of learning and the art of teaching. Harvard Education Review, 24, 86-97.

Suchman, L. (1994). Working relations of technology production and use. Computer Supported Cooperative Work, 2, 21-39. http://dx.doi.org/10.1007/BF00749282

Tabachnick, B. G., \& Fidell, L. S. (2001). Using Multivariate Statistics. Boston: Allyn and Bacon.

Tarter, C., \& Hoy, W. (2004). A systems approach to quality in elementary schools: A theoretical and empirical analysis. Journal of Educational Administration, 42(5), 539-554. https://doi.org/10.1108/09578230410554052

Trochim, W. M., \& Donnelly, J. P. (2006). The research methods knowledge base (3rd ed.). Cincinnati, OH: Atomic Dog.

Versland, T. (2009). Self-efficacy development of aspiring principals in education leadership preparation programs. Library Catalog. Retrieved April 4, 2014, from http://isbn.lib.montana.edu/uhtbin/cgisirsi/x/0/0/57/5?user_id=webbz\&password=web19bz\&1 ibrary $=$ BOZEMAN\&searchdata $1=1428792 \% 7 \mathrm{BCKEY} \% 7 \mathrm{D}$

Vygotsky, L. S. (1962). Thought and language. Cambridge: M.I.T. Press, Massachusetts Institute of Technology. https://doi.org/10.1037/11193-000

Vygotsky, L. S. (1978). Mind in society: The development of higher psychological processes. Cambridge, MA: Harvard University Press. 
Walton, G. M. (2014). The New Science of Wise Psychological Interventions. Current Directions in Psychological Science, 23(1), 73-82. https://doi.org/10.1177/09637214135 12856

Watson, J. B. (1924). Behaviorism. New York: Norton.

\section{Appendix}

Appendix A. Project for Educational Research That Scales (PERTS) survey scale

\begin{tabular}{|c|c|c|c|c|c|c|}
\hline & $\begin{array}{l}\text { Strongly } \\
\text { disagree }\end{array}$ & Disagree & $\begin{array}{l}\text { Somewhat } \\
\text { disagree }\end{array}$ & $\begin{array}{l}\text { Somewhat } \\
\text { agree }\end{array}$ & Agree & $\begin{array}{l}\text { Strongly } \\
\text { agree }\end{array}$ \\
\hline $\begin{array}{l}\text { 1. You can learn new things, but } \\
\text { you can't really change your basic } \\
\text { intelligence/how smart you are. }\end{array}$ & & & & & & \\
\hline $\begin{array}{l}\text { 2. Your intelligence is somethin } \\
\text { about you that you can't change } \\
\text { very much. }\end{array}$ & & & & & & \\
\hline $\begin{array}{l}\text { 3. You have a certain amount of } \\
\text { intelligence, and you really can't d } \\
\text { much to change it. }\end{array}$ & & & & & & \\
\hline $\begin{array}{l}\text { 4. I feel like I belong in this } \\
\text { class. }\end{array}$ & & & & & & \\
\hline 5. I feel respected in this class. & & & & & & \\
\hline 6. I feel comfortable in this clas & & & & & & \\
\hline $\begin{array}{l}\text { 7. I feel like I can be myself in } \\
\text { this class. }\end{array}$ & & & & & & \\
\hline $\begin{array}{l}\text { 8. My class gives me useful } \\
\text { preparation for what I plan to do in } \\
\text { life. }\end{array}$ & & & & & & \\
\hline $\begin{array}{l}\text { 9. This class teaches me valuabl } \\
\text { skills. }\end{array}$ & & & & & & \\
\hline $\begin{array}{l}\text { 10. Working hard in this class } \\
\text { matters for success in my future. }\end{array}$ & & & & & & \\
\hline
\end{tabular}




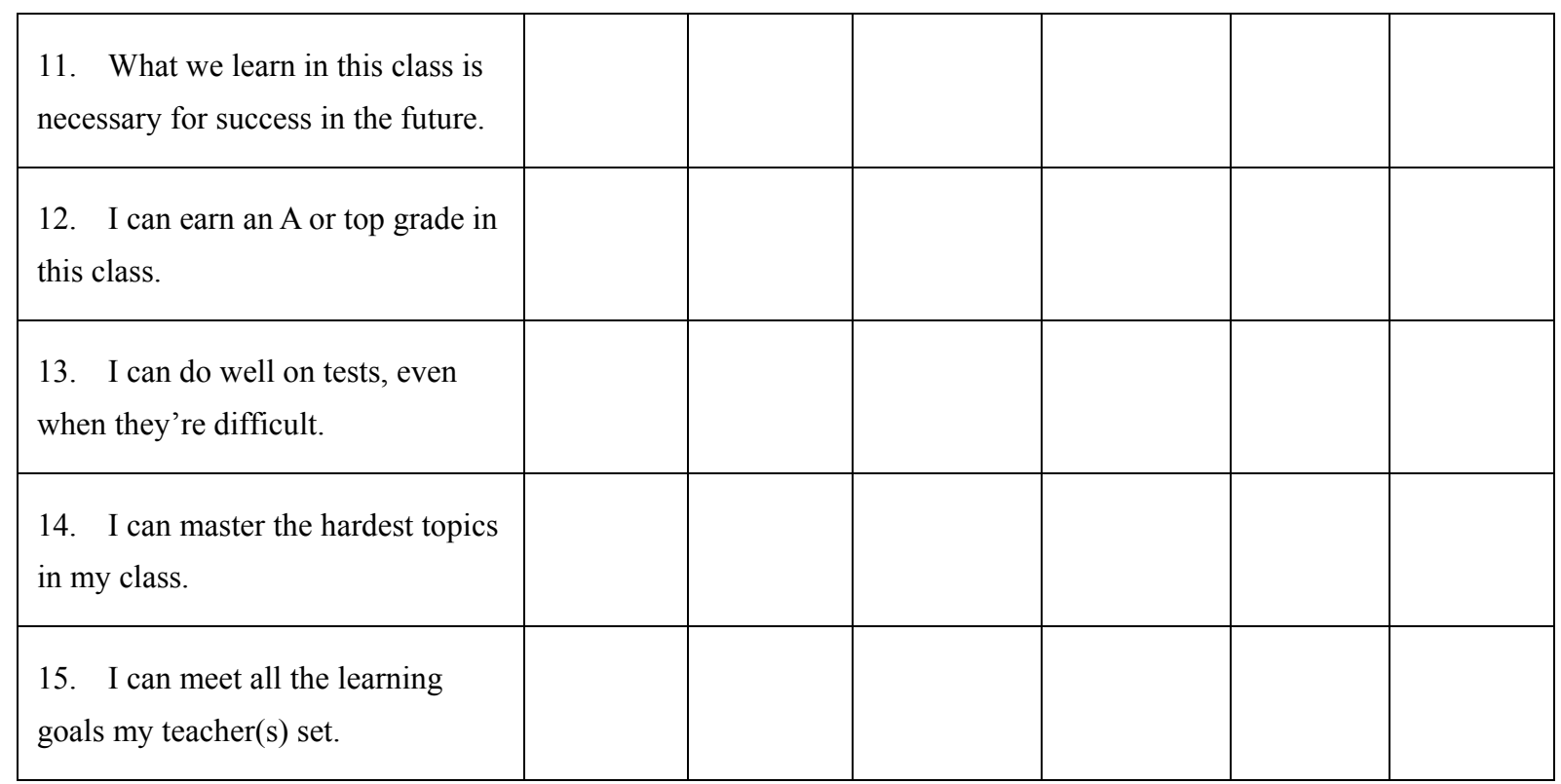

Note. Copyright (C PERTS, 2015.

\section{Copyright Disclaimer}

Copyright for this article is retained by the author(s), with first publication rights granted to the journal.

This is an open-access article distributed under the terms and conditions of the Creative Commons Attribution license (http://creativecommons.org/licenses/by/3.0/). 